\title{
QUAL QUÍMICA ENSINAR? REFLEXÕES A RESPEITO DA EDUCAÇÃO QUÍMICA E FORMAÇÃO DE LEITORES EM AULAS DE QUÍMICA NO ENSINO MÉDIO
}

\author{
Cristhiane Cunha Flôr ${ }^{1}$ \\ Suzani Cassiani ${ }^{2}$
}

\section{Resumo}

O presente estudo trata de questões ligadas a algumas das abordagens dadas à educação química no ensino médio. Trata-se de uma reflexão teórica que engloba aspectos a serem considerados ao se trabalhar com leituras nesse contexto, como a questão da especificidade da linguagem química, de abordagens ligadas ao cotidiano dos estudantes e à formação de sujeitos leitores em aulas de química.

Palavras-Chave: Leituras; Linguagem Química; Cotidiano

\section{LEITURAS EM AULAS DE QUÍMICA... QUAL QUÍMICA?}

Ensinar química, qual química, para quem, para que? Essas são questões que, do nosso ponto de vista, devem nortear sempre os trabalhos do professor e também dos pesquisadores em Educação Química. Por quê? Porque partimos do princípio de que não faz sentido naturalizar o objeto de ensino como se esse fosse imutável, óbvio, indiscutível. Não é possível deixar de questionar os "quais", os "porquês", os "quem" e incidir o foco de atenção unicamente sobre o "como". Em concordância com Paulo Freire, pensamos que nosso agir, enquanto educadores, deve estar permeado de questionamentos.

\footnotetext{
${ }^{1}$ Doutora em Educação Científica e Tecnológica pela UFSC. Endereço: Rua Padre Anchieta, n. 17, apto 203, Bairro São Mateus, Juiz de Fora, Minas Gerais, CEP 36016-440, Brasil, Fone 32 88836237. Endereço eletrônico: cristhianeflor@yahoo.com.br

${ }^{2}$ Doutora em Educação pela UNICAMP. Endereço: Rua Padre Anchieta, n. 17, apto 203, Bairro São Mateus, Juiz de Fora, Minas Gerais, Brasil, CEP 36016-440, Fone 32 88836237. Endereço eletrônico: suzanicassiani@gmail.com
} 
Não posso estar no mundo de luvas nas mãos constatando apenas. A acomodação em mim é apenas caminho para a inserção, que implica decisão, escolha, intervenção na realidade. Há perguntas a serem feitas insistentemente por todos nós $e$ que nos fazem ver a impossibilidade de estudar por estudar. De estudar descomprometidamente como se misteriosamente, de repente, nada tivéssemos a ver com o mundo, um lá fora e distante mundo, alheado de nós e nós dele (FREIRE,2002, p.86). [grifos nossos]

Essa impossibilidade de "estudar por estudar" levantada por Freire influencia fortemente a perspectiva através da qual realizamos o estudo do qual esse trabalho faz parte ${ }^{3}$. Buscamos os caminhos pelos quais o estudante se faz leitor em aulas de química, no Ensino Médio, porém, muito mais do que um leitor de textos, um leitor do mundo, da realidade que o cerca, das situações cotidianas e também das polêmicas e controvérsias que envolvem (ou não) conhecimentos químicos. A leitura do mundo implica na consideração do contexto e do indivíduo imerso nesse e se constitui em um processo que demanda de criticidade no ato de ler.

[...] que não se esgota na decodificação pura da palavra escrita ou da linguagem escrita, mas que se antecipa e se alonga na inteligência do mundo. A leitura do mundo precede a leitura da palavra, daí que a posterior leitura dessa não possa prescindir da continuidade da leitura daquele. Linguagem e realidade se prendem dinamicamente. A compreensão do texto a ser alcançada por sua leitura crítica implica a percepção das relações entre o texto e o contexto (Idem, 2006, p. 11).

O autor lembra que a leitura não é um ato isolado, porém, permeado de significados advindos de sua intrínseca relação com o contexto, com o mundo. Muitas vezes, no contexto escolar, a leitura é vista como um processo separado do dia-a-dia dos estudantes. É como se ler não tivesse nada a ver com sua realidade nem fosse perpassado por ela, havendo atividades específicas de leitura e momentos estanques para que essa ocorra.

Ao considerar imprescindível a leitura do mundo e pensar o papel do ensino de química nessa leitura, se faz necessário questionar qual química ensinar e, também, trabalhar um pouco as questões envolvidas nesse qual. Em primeiro lugar, é importante esclarecer que não estamos dizendo que existem várias químicas e devemos optar por uma delas no contexto da educação. A química, enquanto ciência, utiliza-se de paradigmas bem estabelecidos (numa visão kuhniana de ciência) e de uma linguagem própria para comunicar seus progressos. No entanto, dentro dessa aparente uniformidade há controvérsias, questões polêmicas que envolvem as relações da química com a tecnologia e a sociedade, por exemplo.

\footnotetext{
${ }^{3}$ Tese de Doutorado intitulada "Leitura e Formação de Leitores em aulas de Química no ensino médio", defendida no PPGECT/UFSC em 2009.
} 
Também faz parte desse "qual química ensinar" a compreensão de que como ciência, a química se utiliza de uma linguagem única, no contexto de seu ensino a forma de se posicionar diante dela vai permitir que se desdobre em "química para o vestibular", "química do cotidiano", "química para a cidadania”, "química experimental”, "química teórica” entre tantos outros adjetivos que possa assumir. E essa não é simplesmente uma questão de formas diferentes de nomear a mesma coisa, mas de posicionamentos diferentes que se pode assumir e que envolvem compreensões de ensino, aprendizagem, ciência e currículo. É diante dessa complexidade que perguntamos: qual química ensinar?

A disciplina de química no Ensino Médio costuma ser lecionada através de um enfoque essencialmente positivista, tendo no professor um transmissor de conhecimentos a um receptor passivo. Trabalha-se ensinando conceitos bem estabelecidos na comunidade científica e que servirão de base para a aquisição de novos conceitos para o próximo bimestre, semestre ou ano letivo. Dessa forma, quando os estudantes questionam o porquê de se estudar química, a resposta mais comum é a de que aquele conteúdo é necessário para adquirir os próximos conteúdos, para ter um diploma, passar no vestibular e, fazendo uma faculdade, ser "alguém" na vida. Como se a diferença que um indivíduo faz na sociedade em que vive se aprendesse unicamente nos bancos da universidade e a química fosse mais um dos duros degraus a ser percorrido nessa "escalada".

Não estamos com essas considerações sugerindo que os conceitos químicos tenham pouca importância ou relevância no processo de ensino. Pelo contrário, para participar da tomada de decisões frente a questões cotidianas e a polêmicas que envolvam aspectos químicos, percebemos a necessidade de o indivíduo ter os conhecimentos necessários e pertinentes ao que está sendo discutido. No entanto, apenas conhecimento não basta. $\mathrm{O}$ indivíduo precisa ter noção do poder de ação que a aquisição desses conhecimentos lhe possibilita. Concordamos com Santos e Schnetzler (1997) na visão de que

A presença da química no dia-a-dia das pessoas é mais do que suficiente para justificar a necessidade de o cidadão ser informado sobre química. Todavia, o ensino atual de nossas escolas está muito distante do que o cidadão necessita conhecer para exercer sua cidadania (Idem, p. 13).

Para alguns educadores, as visões positivistas, hierárquicas e compartimentalizadas do ensino e do estudante como depositário de informações causam inquietação, indagações. Será possível aliar o ensino de conceitos químicos ao preparo dos estudantes para a atuação e tomada de decisões sobre assuntos que envolvam esses mesmos conceitos? Como romper essa 
barreira do descomprometimento e trazer o mundo para as aulas de química, e/ou a química para a compreensão do mundo?

Nesse contexto, ressurgem questionamentos que precisam ser discutidos: Qual química ensinar? A química das fórmulas e símbolos? A química do dia-a-dia, impregnada do cotidiano dos estudantes? É importante considerar, em primeiro lugar, que ensinar a química de um desses pontos de vista não exclui automaticamente outros. É possível lançar olhares diferenciados para a química nas situações educacionais e pensamos que essa perspectiva é enriquecedora e contribui em muito com a formação dos estudantes.

\section{FÓRMULAS, SÍMBOLOS, EQUAÇÕES... A QUESTÃO DA LINGUAGEM QUÍMICA}

A respeito da linguagem química e suas implicações na educação, Chassot (2003) ressalta que

A Ciência pode ser considerada como uma linguagem construída pelos homens e pelas mulheres para explicar o mundo natural. Compreendermos essa linguagem (da Ciência) como entendemos algo escrito numa língua que conhecemos (por exemplo, quando se entende um texto escrito em português) - é podermos compreender a linguagem na qual está (sendo) escrita a natureza (CHASSOT, 2003, p.30).

E sobre as dificuldades em ler textos de química e compreender a forma pela qual estão escritos, o autor continua:

Também é verdade que nossas dificuldades diante de um texto em uma língua que
não dominamos podem ser comparadas com as incompreensões para explicar muitos
dos fenômenos que ocorrem na natureza. Por exemplo, é provável que alguns dos
leitores desse texto não saibam distinguir se uma página de um livro ou de uma
revista está escrita em sueco ou em norueguês, assim como deve haver nórdicos que
talvez não reconheçam a diferença entre um texto em português e um em espanhol.
Essa é a analogia que busco quando falo da ciência como uma linguagem (Idem,
p.30).

O autor coloca a ciência como uma linguagem na qual a natureza está escrita. A essa visão, contraponho a ideia de que a ciência utiliza uma linguagem própria e diferenciada para escrever e descrever os fenômenos da natureza. Sem reduzir a ciência à linguagem, queremos apontar, assim como Chassot, para a necessidade de estar "iniciado" nessa para poder compreender o que ela procura dizer. E isso, alguns dos estudantes e professores atualmente não vislumbram, o que traz importantes consequências para o ensino de química. 
Para compreender como se deu a formação da linguagem química que utilizamos atualmente, uma perspectiva histórica pode trazer algumas contribuições. Na transição entre o misticismo ligado à alquimia e a instituição da química enquanto ciência, a linguagem química teve um papel fundamental. Lavoisier em sua marcha contra a teoria do flogístico percebeu a necessidade de criar uma terminologia nova e reformar a nomenclatura da química. Para ele, se expressar de forma clara era tão importante quanto ser rigoroso nos experimentos e raciocinar lucidamente. Lavoisier considerava que

A palavra deve ocasionar o nascimento da ideia; a ideia deve retratar o fato; são três gravuras da mesma estampa. E como são palavras que preservam e transmitem ideias, o resultado é que é impossível melhorar a ciência sem melhorar sua linguagem (LAVOISIER apud BELL, 2007, p. 125).

Visando essa melhoria na química, propôs que não se atribuísse arbitrariamente nomes às substâncias, mas se recorresse à sua composição. Bell (2007) ressalta que

Enquanto os nomes e termos anteriores na química haviam sido sobrepostos, pela teoria, aos fatos observáveis, os termos da nova nomenclatura derivavam da análise das substâncias, baseando-se, na maior parte, em resultados de laboratório explícitos e bem confirmados (Idem, p. 127).

Antes da proposição de Lavoisier, os nomes das substâncias estavam bastante ligados às propriedades que podiam ser percebidas por nossos sentidos. Após as mudanças propostas por Lavoisier, as substâncias chamadas de vitríolo verde e chamado de vitríolo azul no âmbito da alquimia, por exemplo, passaram a chamar-se sulfato de ferro (II) heptahidratado $\left(\mathrm{FeSO}_{4} .7 \mathrm{H}_{2} \mathrm{O}\right)$ e sulfato de cobre (II) pentahidratado $\left(\mathrm{CuSO}_{4} .5 \mathrm{H}_{2} \mathrm{O}\right)$.

Nos exemplos, podemos ver todo o poder de síntese que essa nova linguagem representou. Em um só movimento, o nome das substâncias passou a representar também sua composição. Lavoisier preocupava-se também com o ensino da química e pensava que essa revolução na linguagem auxiliaria muito nos estudos químicos.

Uma linguagem bem-feita, uma linguagem em que tenhamos nos apossado da ordem natural e sucessiva das ideias, traz consigo uma revolução rápida e necessária à forma de ensinar; ela não permite que aqueles que professam a química se extraviem da marcha da natureza; eles devem rejeitar a nomenclatura ou seguir irresistivelmente o caminho que essa traçou (Ibidem, p. 126).

A proposição de Lavoisier ganhou força e foi aos poucos incorporada ao fazer científico na química. Com isso, a descrição de processos e reações deixou de ser expressa em 
palavras e passou a sê-lo através de símbolos e fórmulas. Isto permitiu grandes avanços na ciência, que contava agora com uma linguagem compreendida em todo o mundo, independente da língua falada no país em que era praticada.No contexto educacional, esse potencial de síntese da linguagem química é bastante controverso. Machado (2004) tece considerações a esse respeito ao afirmar que

\begin{abstract}
a linguagem não é apenas um veículo que transporta um conteúdo. A função comunicativa é uma das funções da linguagem e não podemos negar que no processo de construção de conhecimentos em sala de aula há uma dimensão que implica a transmissão de conteúdos. Mas é fundamental ampliarmos nossa concepção de linguagem e considerar sua dimensão constitutiva de nossas formas de pensar e do processo de significação (MACHADO, 2004, p. 133).
\end{abstract}

Essa ampliação da visão da linguagem enquanto constitutiva de nossa forma de pensar é muito importante para o trabalho em aulas de química. Pensar quimicamente também é fazêlo através de símbolos, fórmulas, modelos que estão imersos em teorias e leis.

A água, por exemplo, é uma substância que tem sua importância reconhecida unanimemente. É incontestável seu papel na manutenção da vida no planeta, e são constantemente discutidos soluções e caminhos para sua conservação. Olhar a água através da química, no entanto, implica em fazê-lo também através da elaboração de uma fórmula para sua representação $\left(\mathrm{H}_{2} \mathrm{O}\right)$ e dos modelos que estão embasando essa fórmula, como o modelo atômico e o modelo das ligações químicas covalentes, por exemplo. Por isso a forma de pensar deve ser considerada ao se trabalhar com a linguagem química. Se, por um lado, a fórmula em si remete à substância, por outro, remete também a um conjunto de condições e conhecimentos que sustentam as explicações químicas a respeito da existência dessa substância.

Essas considerações a respeito da química, enquanto forma de pensar o mundo, transcendem o aspecto lógico-matemático dessa ciência. Não se trata de enfatizar esses aspectos em detrimento das visões de ciência e tecnologia que podem e devem ser trabalhadas. A esse respeito, Chassot (1995) lembra que

há também os que vêem no ensino de Química uma oportunidade para ensinar o aluno a pensar. Se fosse esse o objetivo principal, então não deveríamos ensinar Química. Ensinar a jogar xadrez não só cumpre essa finalidade melhor, como é mais atraente. Se o ensino tivesse essa finalidade, não se deveria ter tirado o ensino de latim da escola; é provável que, com o latim, os estudantes desenvolvessem um melhor raciocínio do que aprendendo configurações eletrônicas ou ajustando equações (Idem, p. 40). 
Geralmente a linguagem no âmbito da Educação Química é trabalhada unicamente em sua função comunicativa mencionada anteriormente por Machado (2004). Os professores colocam a fórmula $\mathrm{H}_{2} \mathrm{O}$ e pressupõem a compreensão de todo o restante, como se os estudantes passassem naturalmente da linguagem comum para a linguagem química. É a visão educacional de transmissão de conhecimentos operando.

Pensamos que é necessário trabalhar com os estudantes o fato de que a química tem sua linguagem própria e articulada. Não se trata apenas de um monte de palavras desconhecidas e estranhas relacionadas a outro monte de símbolos e fórmulas que precisam ser decorados. Machado (2004) ao falar sobre o registro reações químicas, ressalta que

Há, nesse sentido, uma certa tradução da linguagem descritiva do fenômeno para a linguagem sintética da equação. Essa tradução é seletiva pois simplifica ao traduzir, não inclui tudo, não inclui a fumaça, a cor, a luz. Mas, pedagogicamente, parece importante que os alunos percebam essa possibilidade de transitar entre esses dois gêneros: a descrição do fenômeno e a equação química (Idem, p.134).

Como exemplo, podemos ver a reação de neutralização entre ácido clorídrico e hidróxido de sódio escrita das duas formas: Colocar em um tubo de ensaio $1 \mathrm{~mL}$ de HCL 1 mol/L. Em outro tubo de ensaio colocar a mesma quantidade de $\mathrm{NaOH} 1 \mathrm{~mol} / \mathrm{L}$, misturar os dois conteúdos.

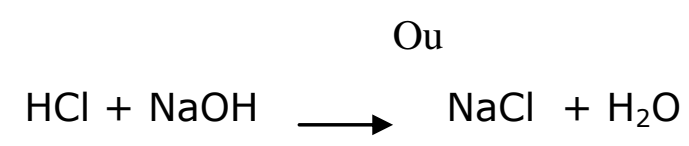

Às vezes, os professores tendem a tratar a representação do fenômeno em forma de equação como se a relação entre os dois fosse óbvia. Isto ocorre em parte porque, para ele, que tem formação em química e fala a partir da posição do cientista, a ligação entre o descrito e o equacionado realmente é direta. Eles não percebem que para o estudante, que está sendo iniciado nos conhecimentos químicos, essa relação não é transparente, direta.

No domínio da Análise do Discurso de Linha Francesa, é possível falar sobre a ilusão da transparência da linguagem, de acordo com a qual se tem a ilusão de que é possível "atravessar" o texto e ter acesso a um sentido único por ele produzido. Fazendo um paralelo, é como se para esses professores bastasse ao estudante "atravessar" a equação e encontrar o significado estável dos símbolos e fórmulas ali representados. É como se esses significados não precisassem ser construídos e fossem os mesmos independentemente da posição da qual o estudante lê. 
Para falar, escrever e compreender química é preciso posicionar-se em relação à sua linguagem, participar de uma formação discursiva que, segundo Orlandi, "se define como aquilo que numa formação ideológica dada - ou seja, a partir de uma posição dada em uma conjuntura sócio histórica dada - determina o que pode e deve ser dito" (2005, p. 43).

A autora salienta ainda que aquilo que o sujeito diz pode adquirir sentidos diversos dependendo da formação discursiva a partir da qual ele fala. Então, falando da formação discursiva química, água pode significar uma molécula covalente polar, por exemplo, ou um solvente, enquanto falando da formação discursiva de agricultores, pode significar possibilidade de irrigação.

[...] a linguagem química não é importante apenas porque vai registrar o fenômeno de uma forma mais concisa e simplificada, mas que ao registrar o fenômeno dessa forma vai configurar os limites e as possibilidades de um certo lugar de observação desse fenômeno. Então, a partir dessas considerações, eu poderia apontar aqui que esse "ensinar nomenclatura" de compostos, esse "aprender a representar fórmulas estruturais" de forma mecânica, como se faz, pouco pode contribuir para a formação do pensamento químico nesse sentido que estou considerando (MACHADO, 1999, p.127-128).

Ao tomar consciência de que quando fala quimicamente o faz a partir de uma formação discursiva, que determina o que pode e/ou deve ser dito, o estudante pode aprender a transitar entre linguagem comum e linguagem científica. Pode também construir, aos poucos, seu aprendizado da linguagem química especificamente.

Se diante da questão sobre qual química ensinar a uma das opções é a química das fórmulas, símbolos e equações, vemos que ainda assim há muito que avançar no sentido de buscar como fazê-lo.

\section{QUÍMICA DO COTIDIANO OU QUÍMICA PARA A CIDADANIA?}

Ensinar química pensando o cotidiano, o dia-a-dia dos estudantes e suas relações com a ciência e a tecnologia. Essa é uma forma de pensar a Educação Química que vai além da apreensão e utilização de sua linguagem. Se a compreensão da linguagem química permite ao estudante uma nova forma de pensar o mundo, ela também implica em posicionar-se em um lugar para fazê-lo. E é problematizando esse lugar que se podem criar vínculos e articulações entre o cotidiano dos estudantes e a química vista na escola. 
Pensamos em articular o ensino de química ao cotidiano dos estudantes, e, então, uma questão se torna bastante relevante: o que estamos chamando de cotidiano? Pelissari (1995) define o cotidiano como sendo

o lugar da vida prenhe de possibilidades e com características comuns a todos os homens. Nesse sentido, não há quem esteja apartado de um viver cotidiano, que já se apresente constituído historicamente e do qual os homens se apropriam ao nascer através da socialização. A apropriação do mundo faz-se através do cotidiano vivido (Idem, p.21).

Tecer algumas considerações a respeito do cotidiano torna-se muito importante, pois como a autora alerta, esse não é apartado das vivências do sujeito, mas sim construído através delas. Pensar o cotidiano unicamente como herdado historicamente é negar a participação dos sujeitos e negar-lhes em grande parte a própria possibilidade de viver suas vidas. Mikhail Bakhtin fala a respeito da ilusão do acabamento que imobiliza o sujeito:

\footnotetext{
Se eu mesmo sou um ser acabado e se o acontecimento é algo acabado, não posso viver nem agir: para viver devo estar inacabado, aberto para mim mesmo - pelo menos no que constitui o essencial da minha vida - devo ser para mim mesmo um valor ainda por-vir, devo não coincidir com minha própria atualidade (BAKHTIN apud BRAIT, 1999, p. 284).
}

Esse inacabamento constitutivo do indivíduo permeia suas ações e seu estar no mundo e precisa ser considerado. Na Educação Científica, por exemplo, é muito comum que livros e textos se proponham a trabalhar com o cotidiano dos estudantes, porém o vejam como algo estático, construído sem a participação deles. É por esse viés que em algumas aulas de química se propõe um estudo com rótulos de produtos de limpeza doméstica, por exemplo, visando trabalhar com o cotidiano dos estudantes.

Porém, há que se questionar antes se esses rótulos fazem parte da vivência desse grupo de estudantes, se tem ligações com o seu cotidiano. Historicamente produtos de limpeza doméstica, como sabões, detergentes e água sanitária, por exemplo, fazem parte da vida das pessoas, no entanto, pode haver grupos que não vivenciam alguma forma de interação com eles. Isto ocorre também com temas como efeito estufa, camada de ozônio, entre outros. Por estarem na mídia, muitos professores passam a pensar que esses temas fazem por si só parte do cotidiano dos estudantes. Mas podem não ser vivenciados por eles, pois apesar da informação, não se envolvem com as questões ou não param para refletir sobre elas.

Isso não quer dizer que o que não é vivenciado pelos estudantes não possa ou deva fazer parte das aulas de química, por exemplo. Pelo contrário, pensamos que a educação é um 
espaço de ampliação do mundo dos estudantes e não deve mantê-los presos ao que já conhecem e compõe seu dia-a-dia, mas propiciar também novas possibilidades de contato com o mundo que os cerca e novas formas de pensar e agir nesse mundo. Apenas, não podemos ter a ilusão, como professores, que o nosso cotidiano é também o cotidiano dos estudantes.

Um exemplo de estudo que estabelece relações entre o cotidiano e a educação química no Ensino Médio é o trabalho de Lutfi (1988). O autor apresenta um trabalho desenvolvido em aulas de química orgânica no Ensino Médio (antigo Segundo Grau), nos períodos compreendidos entre 1974 e 1981 na cidade de São Paulo. O autor lembra que as vivências que temos enquanto estudantes no Ensino Médio influencia a forma de sermos professores. Concordo com essa visão, pois quando um estudante não tem experiências diferenciadas, acaba por acreditar que a forma tradicional é a única justificável. Perde-se a capacidade de duvidar e, como lembra Lutfi (1988), já é um grande passo duvidar.

O autor lembra como se deu historicamente a introdução de materiais para o ensino de química vindos dos Estados Unidos, como o CBA e o Chem-Study e aponta para uma característica desses materiais que perdura até hoje: a desconsideração das diferenças existentes entre os diferentes países e populações onde o material foi empregado.

\begin{abstract}
Essa visão modernizadora desconhece a existência de interesses de classe social, o que não é de se estranhar pois desconhece a própria existência de classe na sociedade e a divisão internacional do trabalho e de capital (quando afirma que o problema é basicamente o mesmo nas mais diversas regiões do mundo). Mas essa visão é importante para nós por mostrar que a classe dirigente não tem dúvida sobre o que deve ser ensinado a seus filhos, tanto no Brasil quanto em qualquer outro país. Aí sim os interesses coincidem (Idem, p. 15).
\end{abstract}

Ao apontar que existem interesses de classes no fazer educação o autor salienta que, no caso das reformas educacionais feitas na época, estas serviam a um interesse da classe dominante em propagar uma pretensa igualdade de condições. A esse respeito, quanto mais refletimos sobre a educação química no Ensino Médio, mais percebemos a necessidade de trazer à tona essas questões, da não neutralidade da educação enquanto instituição e da educação química particularmente.

Tanto a legislação representada pela LDB (Lei de Diretrizes e Bases da Educação, 1996) quanto documentos oficiais como os Parâmetros Curriculares Nacionais para o Ensino Médio enfatizam a necessidade de superar uma visão preparatória do Ensino Médio para exames de admissão em universidades em prol de um ensino de química que contemple o dia- 
a-dia dos estudantes e uma preparação para a cidadania. No entanto, os exames admissionais continuam existindo e, em sua maioria, com provas tradicionais, cobrando conhecimentos estanques, desconectados da realidade dos estudantes e visando a formação de cientistas.

Diante dessas considerações, concordamos com Lutfi (1988) no sentido de que as classes dominantes sabem o que lhes convêm, uma vez que as escolas que seus filhos frequentam continuam muitas vezes perpetuando currículos que reforçam a manutenção do status quo. E, lembrando: "Currículo é uma questão de saber, poder e identidade." (SILVA, 1999, p. 148).

Porém, reconhecemos também que as mudanças na legislação já surtem efeito e vêm aos poucos alterando esse quadro. Uma identidade mais crítica vem permeando exames como o ENEM e mesmo alguns vestibulares, levando a mudanças na educação. E, de qualquer forma, é necessário perceber que não são os currículos que devem ser pautados nesses exames, porém, o movimento precisa se dar no sentido contrário: exames pautados nos currículos. As políticas públicas de inclusão social, como a reserva de "cotas" nas universidades públicas também trazem em seu bojo o estímulo à mudança. Isso porque, tendo em vista que são temas polêmicos, aceleram as discussões a respeito da necessidade de mudanças na educação básica.

Lutfi (1988) realizou um trabalho com os estudantes objetivando despertar o interesse pelo conhecimento das substâncias e consequentemente pela química e também fazer com que, por meio da química, os estudantes entendessem as relações econômicas e sociais envolvidas no processo de produção, armazenamento e consumo de alimentos. Trabalhando com rótulos, textos, visitas a supermercados e indústrias no sentido de compreender essas relações, foram tratadas questões relativas ao cotidiano em sua complexidade, envolvendo o conhecimento químico em discussões a respeito da sociedade capitalista de consumo.

$\mathrm{Na}$ etapa em que foi estudada a legislação sobre alimentos, por exemplo, o autor comenta que é proibido o uso de aditivos alimentares quando houver suspeitas de toxicidade e interferir desfavoravelmente em seu valor nutritivo. No entanto, mostra que

\footnotetext{
A margarina, por exemplo, com seus 7 a 9 aditivos, parte de massa branca que é gordura vegetal hidrogenada e sofre toda uma maquiagem para se parecer com a manteiga:

é aromatizada com diacetila

é colorida com beta-caroteno

é tratada com BHA e BHT para não rancificar

é engomada para não endurecer, até se parecer com manteiga.
} 
Toda legislação decorrente dessa é falha, pois está baseada em premissas falsas. O que nela se omite astutamente, é que os aditivos químicos só têm sentido num sistema econômico que tenha como objetivo a reprodução e a acumulação de capital (LUTFI, 1988, p. 41).

Esse enfoque, aliado ao conhecimento químico dos aditivos, trabalha o cotidiano de forma crítica, refletindo sobre ele e propondo novas formas de olhar para o mundo. Lutfi (1997) tece considerações a respeito de mudanças necessárias à Educação Química no Ensino Médio. A respeito da forma como os conteúdos químicos são muitas vezes ensinados, desconectados da vida dos estudantes, o autor destaca que:

se pretendemos ser do nosso tempo, precisamos refletir se seguimos essa sequência formal de conteúdos ou se damos o passo e pegamos tudo o que está embaralhado na vivência com os alimentos, as tintas, os tecidos, as embalagens e neles buscamos as substâncias na mediação entre estrutura e função. (LUTFI, 1997, p. 8)

É muito importante estabelecer relações entre o conteúdo químico e as vivências dos estudantes durante as aulas de química no Ensino Médio. Retomando a ideia de leitura do mundo, de Paulo Freire, o lugar do qual fala o estudante está repleto de conhecimentos, que muitas vezes a escola ignora, e outras tantas vezes tenta esmagar sobrepondo as teorias científicas como incontestáveis. Freire (1988) aponta que:

\footnotetext{
Uma das tarefas essenciais da escola, como centro de produção sistemática do conhecimento, é trabalhar criticamente a inteligibilidade das coisas e dos fatos e sua comunicabilidade. É imprescindível portanto que a escola instigue constantemente a curiosidade do educando em vez de "amaciá-la" ou "domesticá-la". É preciso mostrar ao educando que o uso ingênuo da curiosidade altera a sua capacidade de achar e obstaculiza a exatidão do achado. É preciso por outro lado e, sobretudo, que o educando vá assumindo o papel de sujeito da produção de sua inteligência do mundo e não apenas de recebedor da que lhe seja transferida pelo professor (Idem, p. 124).
}

"Assumir seu papel na compreensão de sua inteligência do mundo" em aulas de química passa por se apropriar da linguagem e, através dela, se posicionar criticamente. Por um lado, o professor não pode negar ao estudante acesso ao conhecimento químico, numa busca por "facilitar" o ensino de química. Por outro lado, não pode transformar esse conhecimento numa visão neutra dos fenômenos e da matéria, como se fosse o único olhar a ser lançado sobre eles. 
Alguns educadores e pesquisadores propõem trabalhar as articulações entre cotidiano e conhecimento químico através de abordagens CTS (Ciência, Tecnologia e Sociedade) ${ }^{4}$. Santos e Schnetzler (1997) realizaram um trabalho de investigação no qual fazem a análise de conteúdo de uma entrevista semiestruturada a educadores químicos brasileiros sobre como entendem e implementam propostas visando educar para a cidadania. No mesmo estudo realizam uma revisão de literatura sobre o movimento social de ensino CTS. Os autores ressaltam a importância da formação para a cidadania e o desenvolvimento de valores éticos no âmbito da Educação Química. Entre outros pontos, destacam que:

[...] o ensino para o cidadão inclui uma compreensão dos produtos e processos tecnológicos usados pela sociedade contemporânea, assim como um entendimento dos mecanismos sociais existentes de que o cidadão dispõe, ou que deve lutar para conseguir, a fim de transformar a sociedade em que está inserido (SANTOS; SCHNETZLER, 1997, p. 101).

A formação para a cidadania passou a ser um forte objetivo do ensino de ciências naturais - especificamente de química - e faz parte também das preocupações do presente estudo. Educar para estar na sociedade de forma ativa e participante, tomando decisões, levantando questionamento, percebendo-se enquanto sujeito ativo nessa. A respeito de cidadania, compreendo-a assim como Pelissari (1995) como sendo "[...] a maneira através da qual os homens materializam sua relação com outros homens e com a sociedade em que vivem" (p. 143).

Temos consciência que esse é um conceito bastante amplo, que envolve diversas esferas da vida social como, por exemplo, as esferas política, ética, moral, valorativa e também aspectos da vida pública e da vida privada. Santos e Schnetzler (1997) no primeiro capítulo de seu livro Educação em Química - Compromisso com a Cidadania, desenvolvem o conceito de cidadania e suas relações com a educação. Sobre a educação e formação da cidadania levantam alguns pontos que considero relevantes destacar:

- a formação da cidadania pode ser auxiliada pela educação sem, contudo, ser ela o único meio para tal;

- a cidadania não é transmitida, e sim, conquistada, logo, sem o envolvimento ativo do aluno pouco a escola pode contribuir na consolidação da cidadania;

\footnotetext{
4 O ensino CTS está voltado para a formação científica do cidadão. Em seu livro Educação em Química,Compromisso com a Cidadania, Wildson Santos e Roseli Schnetzler realizam uma revisão sobre os principais enfoques e abordagens CTS vinculados à Educação Científica, bem como sobre seus objetivos.
} 
- a educação tem o papel de desenvolver no indivíduo o interesse pelos assuntos comunitários, de forma que ele assuma uma postura de comprometimento com a busca conjunta de solução para os problemas existentes.

As questões levantadas insistem em um aspecto que consideramos fundamental ao educar com esse propósito: o estudante é um sujeito ativo no processo de sua educação e da formação para a cidadania. Um desafio que se mostra para a Educação Química então é mobilizar os estudantes, estimulá-los a desenvolver um pensamento crítico em relação aos conteúdos e conceitos químicos que aprendem. E, para além do desenvolvimento desse pensamento crítico, auxiliá-los a fazê-lo numa perspectiva transformadora, que permita agir no mundo e modificar suas vivências. Santos e Schnetzler (1997) lembram que essas mudanças na Educação Química não são simples nem podem ser feitas de forma superficial:

\footnotetext{
Não basta apenas incluir alguns temas sociais ou dinâmicas de simulação ou debates em sala de aula. Não basta apenas provocar determinadas mudanças no processo atual, mas, sobretudo, é necessário que ele passe por uma mudança radical. É preciso ter claro que ensinar para a cidadania significa adotar uma nova maneira de encarar a educação, diferentemente do que se tem feito atualmente no Ensino Médio de química (Idem, p.128).
}

Essa nova maneira de encarar a Educação Química proposta pelos autores precisa ser abraçada por todos aqueles envolvidos com a educação, para que possa ser efetivada verdadeiramente.

\section{ALGUMAS CONSIDERAÇÕES...}

Pensar "Qual química a ensinar” é, a partir da perspectiva que assumimos (dos estudos da linguagem na educação científica), um passo importante no sentido de negar a homogeneidade de nosso objeto de ensino. A química é uma ciência complexa e rica, que se utiliza de uma linguagem própria e de modelos e teorias para explicar o mundo material. É também uma ciência que impacta diretamente em nosso cotidiano, uma vez que o conhecimento das propriedades dos materiais e de suas transformações está presente no dia-adia de todos nós, quer tenhamos consciência disso ou não. Sendo um objeto não homogêneo, não se presta a formas padronizadas de ensino, mas requer reflexões constantes a respeito do como, por que, para que e para quem ensinar. Pensar questões referentes a qual química 
FLÔR, C. C.; CASSIANI S.

ensinar vem, então, contribuir para com essas reflexões e questionamentos, lançando um olhar teórico a algumas configurações que a química pode assumir em salas de aula de Ensino Médio.

\title{
WHICH CHEMISTRY TEACH? REFLECTIONS ABOUT THE CHEMICAL EDUCATION AND FORMATION OF READERS IN CLASSES OF CHEMISTRY IN SECONDARY EDUCATION
}

\begin{abstract}
This study addresses issues related to some approaches given to chemical education in high school. This is a theoretical reflection that adresses aspects to be considered when working with readings in this context, as the question of the specificity of chemical language, approaches related to the daily lives of students and training of readers in chemistry classes.
\end{abstract}

Keywords: Readings; Chemical Language; Daily Lives of Students

\section{QUÉ QUÍMICA ENSEÑAR? REFLEXIONES ACERCA DE EDUCACIÓN QUÍMICA Y FORMACIÓN DE LECTORES EN LAS AULAS DE QUÍMICA EN LA EDUCACIÓN SECUNDARIA}

\begin{abstract}
Resumen
Este estudio se ocupa de cuestiones relacionadas a algunos de los enfoques dados a la enseñanza de la química en la educación secundaria. Se trata de una reflexión teórica que abarca aspectos a considerar cuando se trabaja con lecturas en este contexto, como la cuestión de la especificidad del lenguaje químico, los enfoques relacionados a la vida diaria de los estudiantes y la formación de sujetos lectores en el aula de química.
\end{abstract}

Términos clave: Lecturas; Lenguaje Químico; Cotidiano 


\section{REFERÊNCIAS}

BELL, Madison Smartt. Lavoisier no ano um: o nascimento de uma nova ciência numa era de revolução. Companhia das Letras, 2007.

BRAIT, Beth. A natureza dialógica da linguagem: formas e graus de representação dessa dimensão constitutiva. In: Faraco, C.A., Tezza, C., Castro G. (Org.). Diálogos com Bakhtin. 4 ed. Curitiba: Editora UFPR, v. 1, 2007, p. 61-80.

CHASSOT, Attico Inácio. Educação ConSciência. 1. ed. Santa Cruz do Sul: Editora EDUNISC, v. 1. 2003.

. Catalisando transformações na Educação. 3. ed., v. 1, Ijuí: Unijuí.1995.

FREIRE, Paulo. Pedagogia da Autonomia: saberes necessários à prática dducativa. São Paulo: Paz e Terra, 2002.

. A Importância do Ato de Ler: em três artigos que se completam. 22 ed. São Paulo:

Cortez, 1988. 80 p.

FLÔR, Cristhiane Cunha. Leitura e formação de leitores em aulas de química no ensino médio. Tese de Doutorado. Programa de Pós Graduação em Educação Científica e Tecnológica/ UFSC. 2009.

LUTFI, Mansur. A abordagem sociológica do Ensino de Química. Campinas: Ciência \& Ensino. v. 3, p. 7-9.1997.

Cotidiano e educação em química. Ijuí: Unijuí, 1988.

MACHADO, Andréa Horta. Aula de Química: discurso e conhecimento. 1. ed. v. 1. 200 p. Ijuí: Editora UNIJUÍ, 2004.

ORLANDI, Eni Puccinelli. Análise de discurso: Princípios e procedimentos. Campinas: Pontes, $5^{\text {a }}$ ed., 2003. Edição 2005.

PELISSARI, M. A.; SANDOVAL, S. A. M. A condição cidadã: valores éticos na individualidade. Piracicaba: UNIMEP, 1995.

SANTOS, W. L.; SCHNETZLER, R. P. Educação em Química: compromisso com a cidadania. Ijuí: Ed. Unijuí, 1997. 144 p.

SILVA, Tomás Tadeu da. Documentos de identidade: uma introdução às teorias do currículo. Belo Horizonte: Autêntica, 1999.

Data de recebimento: $31 / 07 / 2013$

Data de aceite: 03/02/2016 